\title{
Design Modified Fuzzy PD Gravity Controller with Application to Continuum Robot
}

\author{
Mansour Bazregar, Farzin Piltan, AliReza Nabaee, MohammadMahdi Ebrahimi \\ Research and Development Department, Artificial Control and Robotics Lab., Institute of Advance Science and \\ Technology-SSP, Shiraz, Iran \\ E-mail: Piltan_f@iranssp.com,WWW.IRANSSP.COM
}

\begin{abstract}
Refer to this research, a position modified parallel error-based fuzzy Proportional Derivative (PD) gravity controller is proposed for continuum robot manipulator. The main problem of the pure conventional nonlinear controller was equivalent dynamic formulation in uncertain systems. The main challenge of linear controllers is linearization techniques and the quality of performance. The nonlinear equivalent dynamic problem in uncertain system is solved by applied fuzzy logic theory to modified PD gravity. To estimate the continuum robot manipulator system's dynamic, proportional plus modified derivative with 7 rules Mamdani inference system is design and applied to modified PD gravity methodology. The proportional coefficient of controller is tuned by new methodology in limitation uncertainties. The results demonstrate that the proposed controller is a partly model-free controllers which works well in certain and partly uncertain system.
\end{abstract}

Index Terms - Fuzzy Logic Theory, Modified PD Control, PD Gravity Technique, Online Tuning, Flexible Robot Manipulator

\section{Introduction}

Controller (control system) is a device which can sense information from linear or nonlinear system (e.g., robot arm) to improve the systems performance and the immune system behavior [11-20]. In feedback control system considering that there are many disturbances and also variable dynamic parameters something that is really necessary is keeping plant variables close to the desired value. Feedback control system development is the most important thing in many different fields of safety engineering. The main targets in design control systems are safety stability, good disturbance rejection to reach the best safety, and small tracking error[21-33]. At present, in some applications robot arms are used in unknown and unstructured environment, therefore strong mathematical tools used in new control methodologies to design nonlinear robust controller with an acceptable safety performance (e.g., minimum error, good trajectory, disturbance rejection). Advanced control techniques such as sliding mode controller, feedback linearization methodology, adaptive and robust have been applied to the control of numerous single- axis machines and robotic manipulators. One of the most important partly nonlinear safety controllers is linear plus nonlinear methodology which is used in nonlinear certain and partly uncertain systems. This methodology is used in wide range areas such as in safety control access process; in aerospace applications and in IC engines because this methodology can solve some main challenging topics in safety control access such as resistivity to the external disturbance and stability. Even though, this methodology is used in wide range areas but, PD gravity method has an important drawbacks beside uncertain system in presence of external disturbance. This problem is solved by applied soft computing theory [17-22]. Although the fuzzylogic control is not a new technique, its application in this current research is considered to be novel since it aimed for an automated dynamic-less response rather than for the traditional objective of uncertainties compensation[23-36]. The intelligent tracking control by the fuzzy-logic technique provides a cost-and-time efficient control implementation due to the automated dynamic-less input. This in turn would further inspire multi-uncertainties testing for continuum robot [37-56]. Fuzzy logic theory is used to estimate the system's dynamics. To estimate the continuum robot manipulator's dynamic of system, Mamdani fuzzy inference system is design and applied to inverse dynamic methodology [57-69].

Continuum robots represent a class of robots that have a biologically inspired form characterized by flexible backbones and high degrees-of-freedom structures [1-10]. Theoretically, the compliant nature of a continuum robot provides infinite degrees of freedom to these devices. However, there is a limitation set by the practical inability to incorporate infinite actuators in the device. Most of these robots are consequently under actuated (in terms of numbers of independent actuators) with respect to their anticipated tasks. In other words they must achieve a wide range of configurations with relatively few control inputs. This is partly due to the desire to keep the body structures (which, unlike in conventional rigid-link manipulators or fingers, are required to directly contact the environment) "clean and soft", but also to exploit the extra control authority 
available due to the continuum contact conditions with a minimum number of actuators. For example, the Octarm VI continuum manipulator, discussed frequently in this paper, has nine independent actuated degrees-of-freedom with only three sections. Continuum manipulators differ fundamentally from rigid-link and hyper-redundant robots by having an unconventional structure that lacks links and joints. Hence, standard techniques like the Denavit-Hartenberg (D-H) algorithm cannot be directly applied for developing continuum arm kinematics. Moreover, the design of each continuum arm varies with respect to the flexible backbone present in the system, the positioning, type and number of actuators. The constraints imposed by these factors make the set of reachable configurations and nature of movements unique to every continuum robot. This makes it difficult to formulate generalized kinematic or dynamic models for continuum robot hardware. Thus, the kinematics (i.e. geometry based modeling) of a quite general set of prototypes of continuum manipulators has been developed and basic control strategies now exist based on these. The development of analytical models to analyze continuum arm dynamics (i.e. physics based models involving forces in addition to geometry) is an active, ongoing research topic in this field. From a practical perspective, the modeling approaches currently available in the literature prove to be very complicated and a dynamic model which could be conveniently implemented in an actual device's realtime controller has not been developed yet. The absence of a computationally tractable dynamic model for these robots also prevents the study of interaction of external forces and the impact of collisions on these continuum structures. This impedes the study and ultimate usage of continuum robots in various practical applications like grasping and manipulation, where impulsive dynamics [1-10] are important factors. Although continuum robotics is an interesting subclass of robotics with promising applications for the future, from the current state of the literature, this field is still in its stages of inception.

This method is based on design modified fuzzy PD gravity controller and resolves the uncertainty term by fuzzy logic methodology. To have the best performance modified PD method based on boundary derivative methodology is design and to tune the fuzzy logic gain updating factor as well as improve the output performance the iteration algorithm based on Gradient
Descent Optimal Algorithm (GDOA) is introduced. The gain updating factor of this controller is adjusted off line depending on the iterations.

This paper is organized as follows; section 2, is served as an introduction to PD gravity method and its application to control of continuum robot, dynamic of continuum robot and fuzzy inference system. Part 3, introduces and describes the methodology algorithm. Section 4 presents the simulation results and discussion of this algorithm applied to a continuum robot and the final section describe the conclusion.

\section{Theory}

Dynamic Formulation of Continuum Robot: The Continuum section analytical model developed here consists of three modules stacked together in series. In general, the model will be a more precise replication of the behavior of a continuum arm with a greater of modules included in series. However, we will show that three modules effectively represent the dynamic behavior of the hardware, so more complex models are not motivated. Thus, the constant curvature bend exhibited by the section is incorporated inherently within the model. The model resulting from the application of Lagrange's equations of motion obtained for this system can be represented in the form

$$
F_{\text {coeff }} \underline{\tau}=D(\underline{q}) \underline{\ddot{q}}+C(\underline{q}) \underline{\dot{q}}+G(\underline{q})
$$

where $\tau$ is a vector of input forces and $\mathrm{q}$ is a vector of generalized co-ordinates. The force coefficient matrix $F_{\text {coeff }}$ transforms the input forces to the generalized forces and torques in the system. The inertia matrix, $D$ is composed of four block matrices. The block matrices that correspond to pure linear accelerations and pure angular accelerations in the system (on the top left and on the bottom right) are symmetric. The matrix $C$ contains coefficients of the first order derivatives of the generalized co-ordinates. Since the system is nonlinear, many elements of $C$ contain first order derivatives of the generalized co-ordinates. The remaining terms in the dynamic equations resulting from gravitational potential energies and spring energies are collected in the matrix $G$. The coefficient matrices of the dynamic equations are given below,

$$
\begin{aligned}
& \text { Fcoeff }= \\
& {\left[\begin{array}{cccccc}
1 & 1 & \cos \left(\theta_{1}\right) & \cos \left(\theta_{1}\right) & \cos \left(\theta_{1}+\theta_{2}\right) & \cos \left(\theta_{1}+\theta_{2}\right) \\
0 & 0 & 1 & 1 & \cos \left(\theta_{2}\right) & \cos \left(\theta_{2}\right) \\
0 & 0 & 0 & 0 & 1 & 1 \\
1 / 2 & -1 / 2 & 1 / 2 & -1 / 2 & 1 / 2+s_{2} \sin \left(\theta_{2}\right) & -1 / 2+s_{2} \sin \left(\theta_{2}\right) \\
0 & 0 & 1 / 2 & -1 / 2 & 1 / 2 & -1 / 2 \\
0 & 0 & 0 & 0 & 1 / 2 & -1 / 2
\end{array}\right]}
\end{aligned}
$$




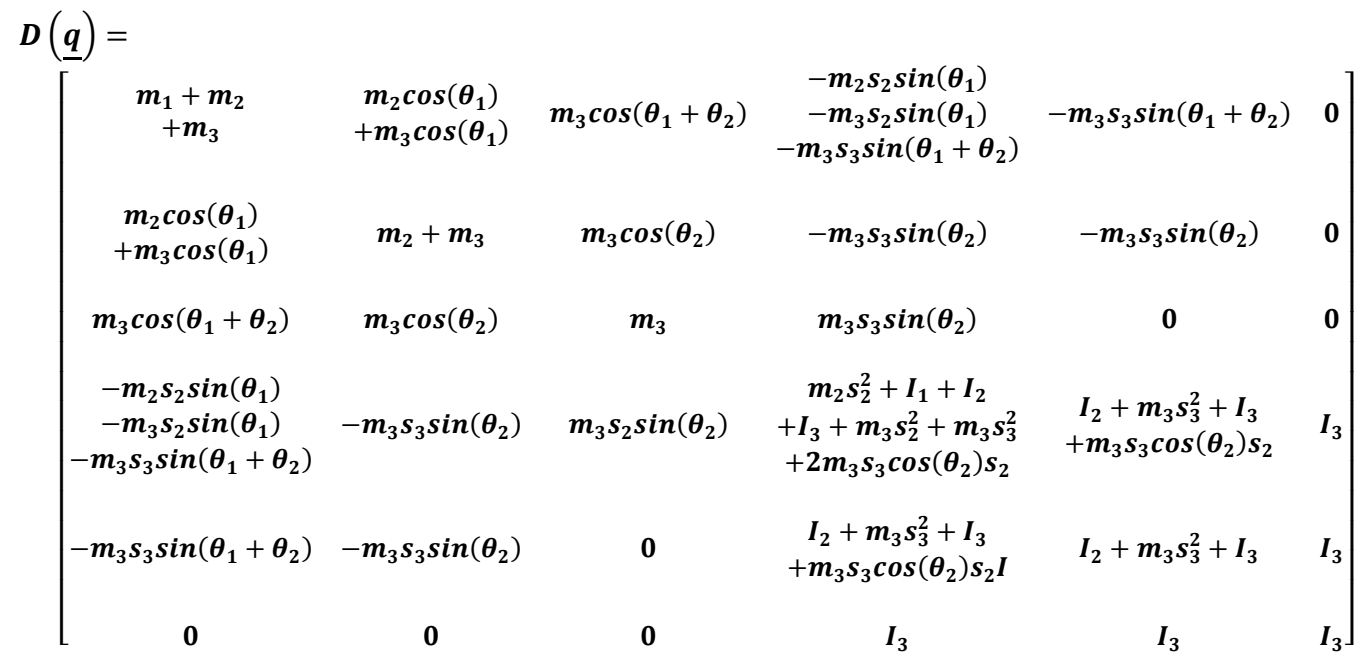

$$
\begin{aligned}
& C(\underline{q})=
\end{aligned}
$$

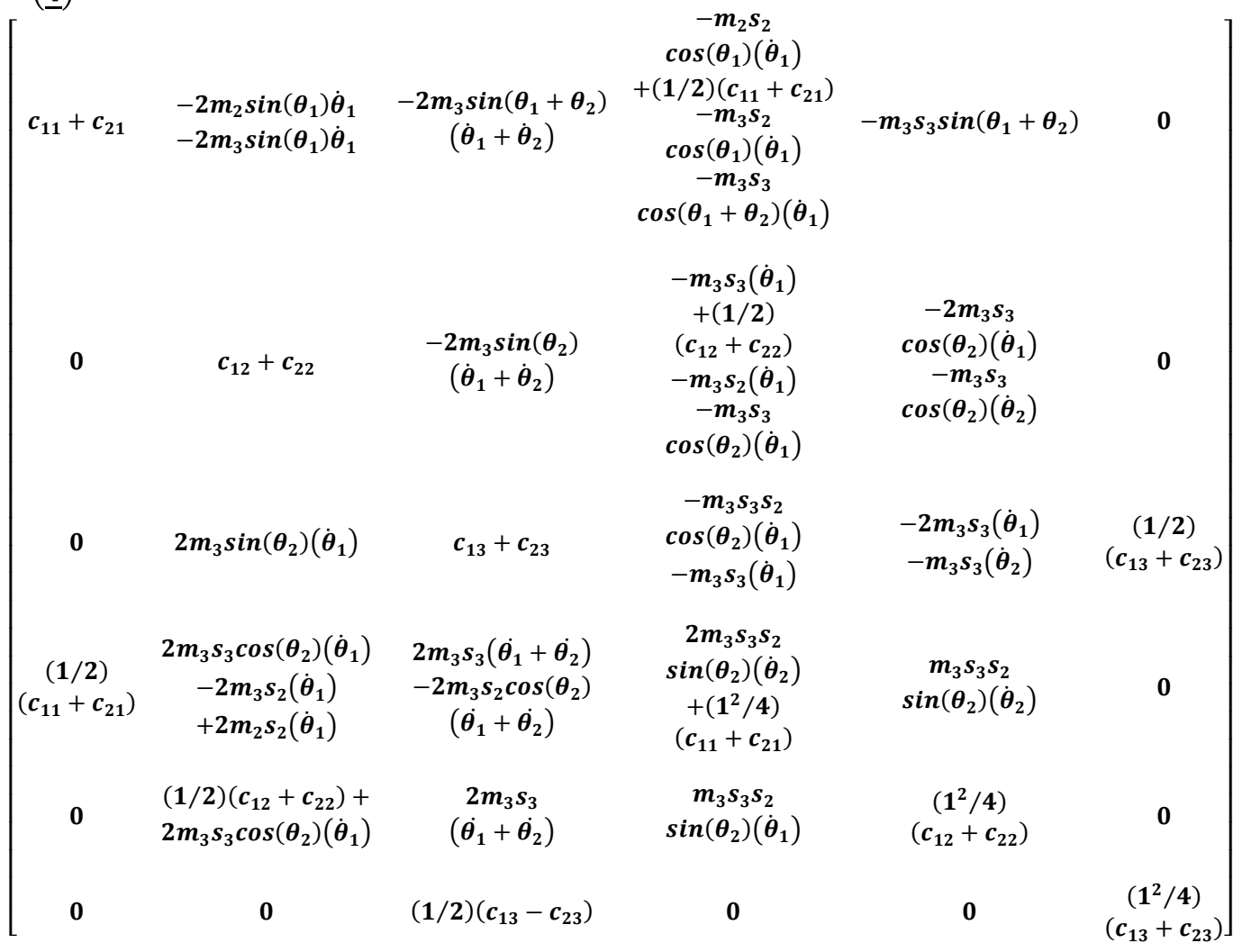

$$
\begin{aligned}
& \boldsymbol{G}(\underline{\boldsymbol{q}})= \\
& {\left[\begin{array}{c}
-m_{1} g-m_{2} g+k_{11}\left(s_{1}+(1 / 2) \theta_{1}-s_{01}\right)+k_{21}\left(s_{1}-(1 / 2) \theta_{1}-s_{01}\right)-m_{3} g \\
-m_{2} g \cos \left(\theta_{1}\right)+k_{12}\left(s_{2}+(1 / 2) \theta_{2}-s_{02}\right)+k_{22}\left(s_{2}-(1 / 2) \theta_{2}-s_{02}\right)-m_{3} g \cos \left(\theta_{1}\right) \\
-m_{3} g \cos \left(\theta_{1}+\theta_{2}\right)+k_{13}\left(s_{3}+(1 / 2) \theta_{3}-s_{03}\right)+k_{23}\left(s_{3}-(1 / 2) \theta_{3}-s_{03}\right) \\
m_{2} s_{2} g \sin \left(\theta_{1}\right)+m_{3} s_{3} g \sin \left(\theta_{1}+\theta_{2}\right)+m_{3} s_{2} g \sin \left(\theta_{1}\right)+k_{11}\left(s_{1}+(1 / 2) \theta_{1}-s_{01}\right)(1 / 2) \\
+k_{21}\left(s_{1}-(1 / 2) \theta_{1}-s_{01}\right)(-1 / 2) \\
m_{3} s_{3} g \sin \left(\theta_{1}+\theta_{2}\right)+k_{12}\left(s_{2}+(1 / 2) \theta_{2}-s_{02}\right)(1 / 2)+k_{22}\left(s_{2}-(1 / 2) \theta_{2}-s_{02}\right)(-1 / 2) \\
k_{13}\left(s_{3}+(1 / 2) \theta_{3}-s_{03}\right)(1 / 2)+k_{23}\left(s_{3}-(1 / 2) \theta_{3}-s_{03}\right)(-1 / 2)
\end{array}\right]}
\end{aligned}
$$


Linear Controller: In the absence of robot knowledge, proportional-integral-derivative (PID), proportionalintegral (PI) and proportional -derivative (PD) may be the best controllers, because they are model-free, and they're parameters can be adjusted easily and separately [22-36] and it is the most used in continuum robot manipulators. In order to remove steady-state error caused by uncertainties and noise, the integrator gain has to be increased. This leads to worse transient performance, even destroys the stability. The integrator in a PID controller also reduces the bandwidth of the closed-loop system. PD control guarantees stability only when the PD gains tend to infinity, the tracking error does not tend to zero when friction and gravity forces are included in the continuum robot manipulator dynamics [37-44]. Model-based compensation for PD control is an alternative method to substitute PID control [45-54], such as adaptive gravity compensation [55-61], desired gravity compensation [62], and PD+ with position measurement [63-69]. They all needed structure information of the robot gravity. Some nonlinear PD controllers can also achieve asymptotic stability, for example PD control with time-varying gains [66], PD control with nonlinear gains [69], and
PD control with feedback linearization compensation [67]. But these controllers are complex; many good properties of the linear PID control do not exist because these controllers do not have the same form as the industrial PID. Design of a linear methodology to control of continuum robot manipulator was very straight forward. Since there was an output from the torque model, this means that there would be two inputs into the PID controller. Similarly, the outputs of the controller result from the two control inputs of the torque signal. In a typical PID method, the controller corrects the error between the desired input value and the measured value. Since the actual position is the measured signal. Figure 1 showS linear PID methodology, applied to continuum robot manipulator [9-16].

$$
\begin{aligned}
& e(t)=\theta_{a}(t)-\theta_{d}(t) \\
& U_{P I D}=K_{p_{a}} e+K_{V_{a}} \dot{e}+K_{I} \sum e
\end{aligned}
$$

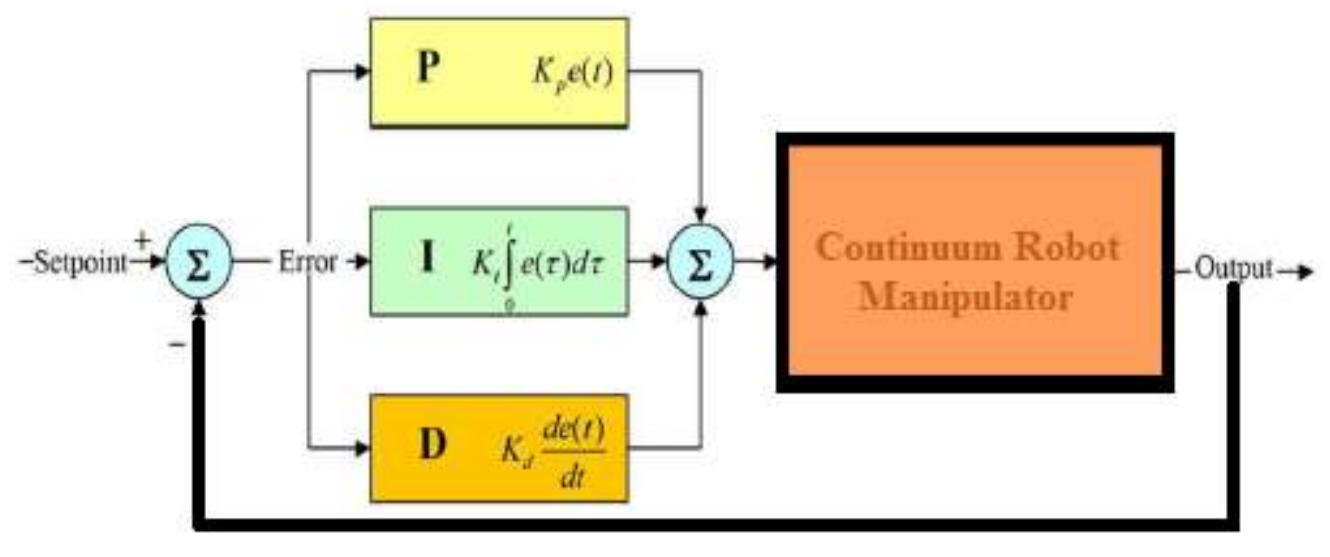

Fig. 1: Block diagram of linear PID method

The model-free control strategy is based on the assumption that the joints of the manipulators are all independent and the system can be decoupled into a group of single-axis control systems [33-45]. Therefore, the kinematic control method always results in a group of individual controllers, each for an active joint of the manipulator. With the independent joint assumption, no a priori knowledge of robot manipulator dynamics is needed in the kinematic controller design, so the complex computation of its dynamics can be avoided and the controller design can be greatly simplified. This is suitable for real-time control applications when powerful processors, which can execute complex algorithms rapidly, are not accessible. However, since joints coupling is neglected, control performance degrades as operating speed increases and a manipulator controlled in this way is only appropriate for relatively slow motion [33-56]. The fast motion requirement results in even higher dynamic coupling between the various robot joints, which cannot be compensated for by a standard robot controller such as PID, and hence model-based control becomes the alternative.

Nonlinear Computed Torque Methodology: computed torque controller (CTC) is one of the powerful nonlinear controllers which can widely used in control of robot manipulator. It is based on feedback linearization and computes the required arm torques based on the nonlinear feedback control law. This controller works very well when all dynamic and physical parameters are known but when the robot manipulator has variation in dynamic parameters, it has many challenges. In practice, most of physical systems (e.g., robot manipulators) parameters are unknown or time variant, therefore, partly computed torque controller (e.g., PD Gravity) used to compensate 
dynamic equation of robot manipulator12-26]. Computed Torque Controller is based on cancelling decoupling and nonlinear terms of dynamics of each link. This control has the form [12-26]:

$$
\begin{gathered}
\tau=D(\boldsymbol{q}) \cdot V+f(\boldsymbol{q})[\dot{\boldsymbol{q}} \dot{\boldsymbol{q}}]+C(\boldsymbol{q})[\dot{\boldsymbol{q}}]^{2} \\
+\boldsymbol{G}(\boldsymbol{q})
\end{gathered}
$$

where typical choices for $V$ are:

$$
V=\ddot{q}_{d}+K_{v}\left(\dot{q}_{d}-\dot{q}_{a}\right)+K_{p}\left(\boldsymbol{q}_{d}-\boldsymbol{q}_{a}\right)
$$

or with an integral term

$$
\begin{aligned}
& v=\ddot{q}_{d}+K_{v}\left(\dot{q}_{d}-\dot{q}_{a}\right)+K_{p}\left(q_{d}-q_{a}\right)+ \\
& K_{I} \int\left(q_{d}-q_{a}\right) d t
\end{aligned}
$$

where $e=\left(q_{d}-q_{a}\right)$, the resulting error dynamics is

$$
\dddot{q}_{d}+K_{v} \ddot{e}+K_{p} \dot{e}+K_{I} e=0
$$

where $\boldsymbol{K}_{\boldsymbol{p}}, \boldsymbol{K}_{\boldsymbol{v}}$ and $\boldsymbol{K}_{\boldsymbol{I}}$ are the controller gains. Based on (11) in inverse dynamic controller; the performance is depended on the gain updating factor $(\boldsymbol{K})$ : derivative gain updating factor $\left(\boldsymbol{K}_{\boldsymbol{v}}\right)$, proportional gain updating factor $\left(\boldsymbol{K}_{\boldsymbol{p}}\right)$ and integral gain updating factor $\left(\boldsymbol{K}_{\boldsymbol{I}}\right)$.

Figure 2 shows the inverse dynamic methodology with application to continuum robot.

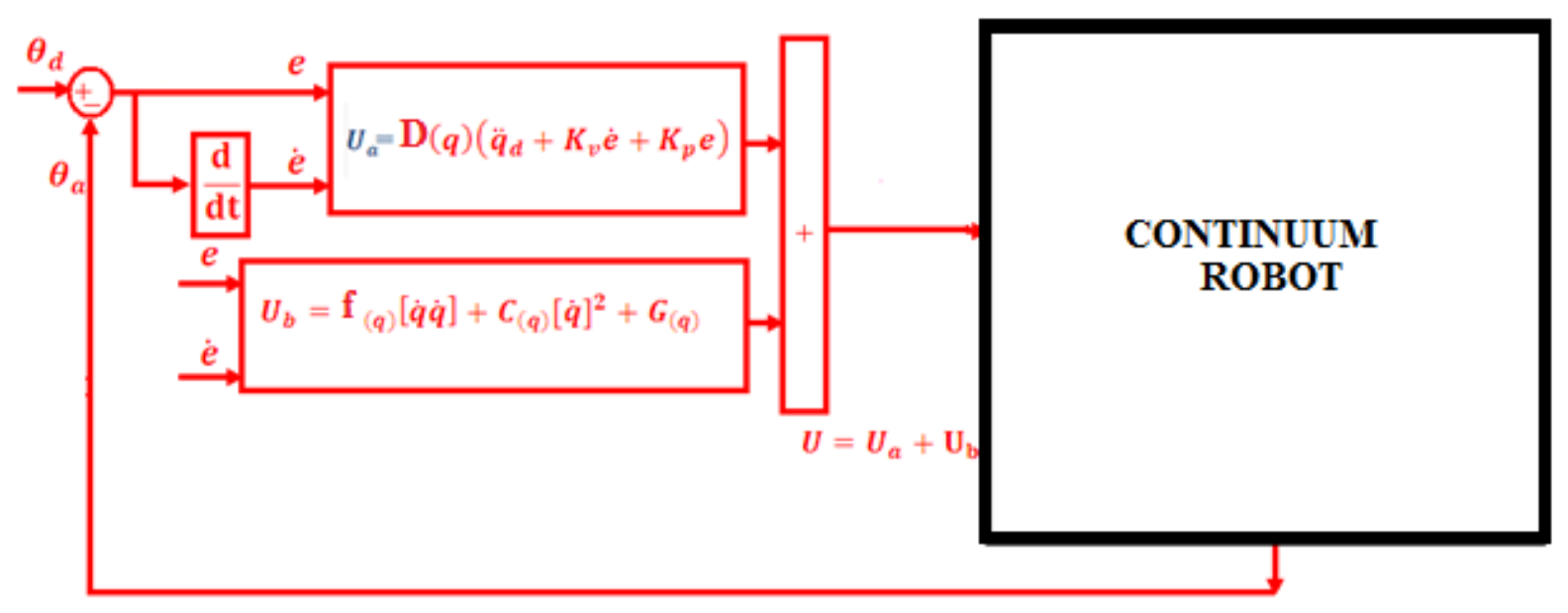

Fig. 2: Block diagram of inverse dynamic methodology

Fuzzy Logic Theory: This section provides a review about foundation of fuzzy logic based on [33-56]. Supposed that $U$ is the universe of discourse and $x$ is the element of $U$, therefore, a crisp set can be defined as a set which consists of different elements $(x)$ will all or no membership in a set. A fuzzy set is a set that each element has a membership grade, therefore it can be written by the following definition;

$$
A=\left\{x, \mu_{A}(x) \mid x \in X\right\} ; A \in U
$$

Where an element of universe of discourse is $x, \mu_{A}$ is the membership function (MF) of fuzzy set. The membership function $\left(\mu_{A}(x)\right)$ of fuzzy set $A$ must have a value between zero and one. If the membership function $\mu_{A}(x)$ value equal to zero or one, this set change to a crisp set but if it has a value between zero and one, it is a fuzzy set. Defining membership function for fuzzy sets has divided into two main groups; namely; numerical and functional method, which in numerical method each number has different degrees of membership function and functional method used standard functions in fuzzy sets. The membership function which is often used in practical applications includes triangular form, trapezoidal form, bell-shaped form, and Gaussian form.

Linguistic variable can open a wide area to use of fuzzy logic theory in many applications (e.g., control and system identification). In a natural artificial language all numbers replaced by words or sentences. If - then Rule statements are used to formulate the condition statements in fuzzy logic. A single fuzzy If then rule can be written by

\section{If $x$ is $A$ Then $y$ is $B$}

where $A$ and $B$ are the Linguistic values that can be defined by fuzzy set, the If - part of the part of " $x$ is $A$ " is called the antecedent part and the then part of the part of " $y$ is $B$ " is called the Consequent or Conclusion part. The antecedent of a fuzzy if-then rule can have multiple parts, which the following rules shows the multiple antecedent rules:

$$
\text { if } e \text { is NB and } \dot{e} \text { is ML then } T \text { is } L L
$$


where $e$ is error, $\dot{e}$ is change of error, $N B$ is Negative Big, $M L$ is Medium Left, $T$ is torque and $L L$ is Large Left. If - then rules have three parts, namely, fuzzify inputs, apply fuzzy operator and apply implication method which in fuzzify inputs the fuzzy statements in the antecedent replaced by the degree of membership, apply fuzzy operator used when the antecedent has multiple parts and replaced by single number between 0 to 1, this part is a degree of support for the fuzzy rule, and apply implication method used in consequent of fuzzy rule to replaced by the degree of membership. The fuzzy inference engine offers a mechanism for transferring the rule base in fuzzy set which it is divided into two most important methods, namely, Mamdani method and Sugeno method. Mamdani method is one of the common fuzzy inference systems and he designed one of the first fuzzy controllers to control of system engine. Mamdani's fuzzy inference system is divided into four major steps: fuzzification, rule evaluation, aggregation of the rule outputs and defuzzification. Michio Sugeno uses a singleton as a membership function of the rule consequent part. The following definition shows the Mamdani and Sugeno fuzzy rule base

$$
\begin{array}{ccr}
\text { Mamdani } & \text { F. } R^{1}: \text { if } & x \text { is A and } \\
\text { y is } B \text { then } & z \text { is } C \\
\text { Sugeno } & \text { F. } R^{1}: \text { if } & x \text { is A and } \\
y \text { is } B & \text { then } & f(x, y) \text { is } C
\end{array}
$$

When $x$ and $y$ have crisp values fuzzification calculates the membership degrees for antecedent part. Rule evaluation focuses on fuzzy operation $(A N D / O R)$ in the antecedent of the fuzzy rules. The aggregation is used to calculate the output fuzzy set and several methodologies can be used in fuzzy logic controller aggregation, namely, Max-Min aggregation, Sum-Min aggregation, Max-bounded product, Max-drastic product, Max-bounded sum, Max-algebraic sum and Min-max. Two most common methods that used in fuzzy logic controllers are Max-min aggregation and Sum-min aggregation. Max-min aggregation defined as below

$$
\begin{aligned}
& \mu_{U}\left(x_{k}, y_{k}, U\right)=\mu_{\cup i=1}^{r} F R^{i}\left(x_{k}, y_{k}, U\right) \\
& =\max \left\{\min _{i=1}^{r}\left[\mu_{R_{p q}}\left(x_{k}, y_{k}\right), \mu_{p_{m}}(U)\right]\right\}
\end{aligned}
$$

The Sum-min aggregation defined as below

$$
\begin{aligned}
& \mu_{U}\left(x_{k}, y_{k}, U\right)=\mu_{\cup i=1}^{r} F R^{i}\left(x_{k}, y_{k}, U\right) \\
& =\sum \min _{i=1}^{r}\left[\mu_{R}\left(x_{k}, y_{k}\right), \mu_{p_{m}}(U)\right]
\end{aligned}
$$

where $r$ is the number of fuzzy rules activated by $x_{k}$ and $y_{k}$ and also $\mu_{\cup_{i=1}^{r} F R^{i}}\left(x_{k}, y_{k}, U\right)$ is a fuzzy interpretation of $i-t h$ rule. Defuzzification is the last step in the fuzzy inference system which it is used to transform fuzzy set to crisp set. Consequently defuzzification's input is the aggregate output and the defuzzification's output is a crisp number. Centre of gravity method $(C O G)$ and Centre of area method $(C O A)$ are two most common defuzzification methods, which $C O G$ method used the following equation to calculate the defuzzification

$$
\operatorname{COG}\left(x_{k}, y_{k}\right)=\frac{\sum_{i} U_{i} \sum_{j=1}^{r} \cdot \mu_{u}\left(x_{k}, y_{k}, U_{i}\right)}{\sum_{i} \sum_{j=1}^{r} \cdot \mu_{u}\left(x_{k}, y_{k}, U_{i}\right)}
$$

and COA method used the following equation to calculate the defuzzification

$$
\operatorname{COA}\left(x_{k}, y_{k}\right)=\frac{\sum_{i} U_{i} \cdot \mu_{u}\left(x_{k}, y_{k}, U_{i}\right)}{\sum_{i} \mu_{U} \cdot\left(x_{k}, y_{k}, U_{i}\right)}
$$

Where $\operatorname{COG}\left(x_{k}, y_{k}\right)$ and $\operatorname{COA}\left(x_{k}, y_{k}\right)$ illustrates the crisp value of defuzzification output, $U_{i} \in U$ is discrete element of an output of the fuzzy set, $\mu_{U} \cdot\left(x_{k}, y_{k}, U_{i}\right)$ is the fuzzy set membership function, and $r$ is the number of fuzzy rules.

Based on foundation of fuzzy logic methodology; fuzzy logic controller has played important rule to design nonlinear controller for nonlinear and uncertain systems [12-16]. However the application area for fuzzy control is really wide, the basic form for all command types of controllers consists of:

- Input fuzzification (binary-to-fuzzy[B/F]conversion)

- Fuzzy rule base (knowledge base)

- Inference engine

- Output defuzzification (fuzzy-to-binary conversion).

Figure 3 shows the block diagram of fuzzy logic control methodology based on two inputs and one output.

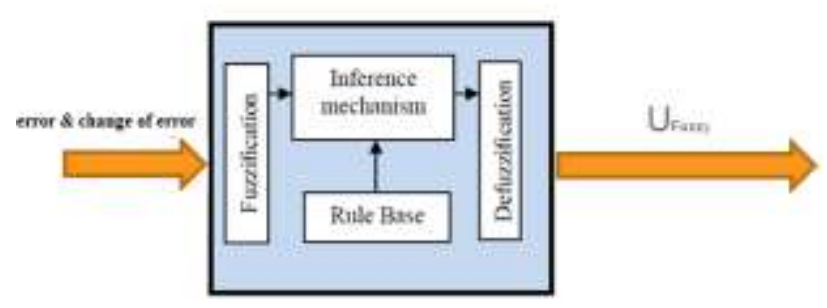

Fig. 3: Block diagram of fuzzy logic control methodology

Gradient Descent Algorithm: Gradient Descent Optimization (GDO) is one of the evolutionary optimization algorithms in the branch of non intelligence [44]. This algorithm was inspired by the social movement behavior of the birds in the flock searching for food. Compared to the other evolutionary algorithms, the main excellences of this algorithm are: Simple concept, easy to implement, robustness in tuning parameters, minimum storage space and both global and 
local exploration capabilities. These birds in a flock are symbolically described as particles. These particles are supposed to a swarm "flying" through the problem space. Each particle has a position and a velocity. Any particle's position in the problem space has one solution for the problem. When a particle transfers from one place to another, a different problem solution is generated. Cost function evaluated the solution in order to provide the fitness value of a particle. "Best location" of each particle which has experienced up to now, is recorded in their memory, in order to determine the best fitness value. Particles of a gradient descent transmit the best location with each other to adapt their own location according to this best location to find the global minimum point. For every generation, the new location is computed by adding the particle's current velocity to its location. GDO is initialized with a random population of solutions in $\mathrm{N}$-dimensional problem space, the $\boldsymbol{i}$ th particle changes and updates its position and velocity according to the following formula:

$$
\begin{aligned}
& V_{i d}=w \times\left(V_{i d}+C_{1} \times \operatorname{rand}_{1} *\left(P_{i d}-\right.\right. \\
& \left.\left.X_{i d}\right)+C_{2} \times \operatorname{rand}_{2} \times\left(P_{g d}-X_{i d}\right)\right)
\end{aligned}
$$

Where $\boldsymbol{X}_{\boldsymbol{i d}}$ is calculated by

$$
X_{i d}=X_{i d}+V_{i d}
$$

Where $\boldsymbol{V}_{\boldsymbol{i d}}$ is the inertia weight implies the speed of the particle moving along the dimensions in a problem space. $\boldsymbol{C}_{\mathbf{1}}$ and $\boldsymbol{C}_{\mathbf{2}}$ are acceleration parameters, called the cognitive and social parameters; rand $_{\mathbf{1}}$ and $\boldsymbol{r a n d}_{\mathbf{2}}$ are functions that create random values in the range of $(0$, 1). $\boldsymbol{X}_{\boldsymbol{i} \boldsymbol{d}}$ is the particle's current location; $\boldsymbol{P}_{\boldsymbol{i d}}$ (personal best) is the location of the particle experienced its personal best fitness value; $\boldsymbol{P}_{\boldsymbol{g} \boldsymbol{d}}$ (global best) is the location of the particle experienced the highest best fitness value in entire population; $\boldsymbol{d}$ is the number of dimensions of the problem space; . $\boldsymbol{W}$ is the momentum part of the particle or constriction coefficient [5] and it is calculated based on the following equation;

$$
\begin{aligned}
& W=2 /\left(2-\varphi-\sqrt{\varphi^{2}-4 \varphi}\right) \\
& \varphi=C_{1}+C_{2} \quad, \quad \varphi>4
\end{aligned}
$$

Equation 10 needs each particle to record its location $\boldsymbol{X}_{\boldsymbol{i d}}$, its velocity $\boldsymbol{V}_{\boldsymbol{i d}}$, its personal best fitness value $\mathbf{P} \boldsymbol{i d}$, and the whole population's best fitness value $\boldsymbol{P}_{\boldsymbol{g} \boldsymbol{d}}$.

On the basis of following equation the best fitness value $\boldsymbol{X}_{i}$ is updated at each generation, where the sign $\boldsymbol{f}($.$) represents the cost function; \boldsymbol{X}_{\boldsymbol{i}}($.$) indicated the$ best fitness values; and $\boldsymbol{t}$ denotes the generation step.

$$
\begin{aligned}
& X_{i}(t+1)= \\
& \left\{\begin{array}{cl}
X_{i}(t) & f\left(P_{d}(t+1)\right) \leq X_{i}(t) \\
f\left(P_{d}(t+1)\right) & f\left(P_{d}(t+1)\right)>X_{i}(t)
\end{array}\right.
\end{aligned}
$$

In GDO, the knowledge of each particle will not be substituted until the particle meets a new position vector with a higher competence value than the currently recorded value in its memory [66-69]. External disturbances influence on tracking trajectory, error rate and torque which result in chattering. But the values are not such a great values and these oscillations are in all physical systems. So, the sliding mode controller can reject perturbations and external disturbances if these parameters adjust properly. So the methodology which is applied in this paper in order to select the best values for these deterministic coefficients to accomplish high performance control is the Gradient Descent Optimization algorithm. This algorithm tunes the gains and determines the appropriate values for these parameters in harmony with the system which was introduced in rear part.

\section{Methodology}

Computed Torque controller (CTC) is an important nonlinear controller in a partly uncertain dynamic system's parameters. Conversely pure CTC is a highquality nonlinear controller; it has an important problem; nonlinear equivalent dynamic formulation in uncertain dynamic parameter. In this research the nonlinear equivalent dynamic (equivalent part) formulation problem in uncertain system is eliminated based on PD Gravity and estimated by fuzzy logic theorem. Fuzzy logic theory is used to estimate of the equivalent part in fuzzy partly linear PD Gravity controller. In this method fuzzy logic theorem is parallel applied to PD Gravity controller to remove the nonlinear equivalent part which it is based on nonlinear dynamic formulation. To achieve this goal, the dynamic equivalent part of pure CTC is modeled by Mamdani's performance/ errorbased fuzzy logic methodology. This technique was employed to obtain the desired control behavior with a number of information about dynamic model of system and a parallel fuzzy control was applied to reinforce system performance. Equivalent part is based on continuum robot manipulator's dynamic formulation which these formulations are nonlinear; MIMO and some of them are unknown. To solve the challenge of CTC based on nonlinear dynamic formulation this research is focused on eliminate the nonlinear equivalent formulation. In this method; dynamic nonlinear equivalent part is replaced by performance/error-based fuzzy logic controller plus gravity term. In this method error based Mamdani's fuzzy inference system has considered with two inputs, one output and totally 49 rules instead of the dynamic equivalent part. In a typical PD method, the controller corrects the error between the desired input value and the measured value. Since the actual position is the measured signal. The derivative part of PD methodology is worked based on change of error and the derivative coefficient. In this research the modified PD is used based on boundary derivative part. 


$$
\begin{aligned}
& \dot{e}(t) \triangleq\left(\frac{S}{0.1 S+1}\right) \times e(t) \\
& U_{P D}=K_{p_{a}} e+K_{V_{a}} \dot{e}
\end{aligned}
$$

This is suitable for real-time control applications when powerful processors, which can execute complex algorithms rapidly, are not accessible. The result of modified PD method shows the power of disturbance rejection in this methodology.

For CTC and parallel fuzzy inverse dynamic controller plus gravity applications the system performance is sensitive to the linear PD coefficient $\left(K_{p} \& K_{v}\right)$. For instance, if large value of $K_{p} \& K_{v}$ are chosen the response is very fast the system is unstable and conversely, if small value of $K_{p} \& K_{v}$ are considered the response of system is very slow but system is stable. Therefore to have a good response, compute the best value linear coefficients are very important. The on-line tuning parallel fuzzy error-based PD Gravity output is written;

$$
\begin{aligned}
& \hat{\mathbf{\tau}}=\tau_{\mathrm{eq}_{\mathrm{fuzzy}}}+\boldsymbol{\tau}_{\text {partly linear }}+\mathbf{G}(\mathbf{q})= \\
& \sum_{l=1}^{M} \boldsymbol{\theta}^{T} \zeta(x)+D(q) \cdot\left[\ddot{q}_{d}+K_{p_{a}} e+\right. \\
& \left.\left(\frac{S}{0.1 S+1}\right) \times e(t) K_{V_{a}}\right]+G(q)
\end{aligned}
$$

Based on fuzzy logic methodology

$$
f(x)=U_{f u z z y}=\sum_{l=1}^{M} \theta^{T} \zeta(x)
$$

where $\theta^{T}$ is adjustable parameter (gain updating factor) and $\zeta(x)$ is defined by;

$$
\zeta(x)=\frac{\sum_{i} \mu\left(x_{i}\right) x_{i}}{\sum_{i} \mu\left(x_{i}\right)}
$$

Where $\mu\left(x_{i}\right)$ is membership function. $\tau_{f u z z y}$ is defined as follows;

$$
\tau_{f u z z y}=\sum_{l=1}^{M} \theta^{T} \zeta(x)=[(f+C)]
$$

Adaption law in this methodology is used to adjust the linear PD coefficient and gain updating factors. Linear error-based tuning part is a supervisory controller based on the following formulation methodology. This controller has three inputs namely; error $(e)$, change of error $(\dot{e})$ and the integral of error $\left(\sum e\right)$ and an output namely; gain updating factor $(\alpha)$. As a summary design a linear error-based tuning is based on the following formulation:

$$
\begin{aligned}
& \alpha=K . e+\dot{e}+\frac{(K)^{2}}{2} \sum e \\
& \boldsymbol{K}_{\boldsymbol{p}_{\boldsymbol{a}}}=\alpha \cdot K_{p} \Rightarrow \boldsymbol{K}_{\boldsymbol{p}_{\boldsymbol{a}}}=(K \cdot e+\dot{e}+ \\
& \left.\frac{(K)^{2}}{2} \sum e\right) K_{p} \\
& \boldsymbol{K}_{\boldsymbol{v}_{\boldsymbol{a}}}=\alpha \cdot K_{v} \Rightarrow \boldsymbol{K}_{\boldsymbol{v}_{\boldsymbol{a}}}=\left(K . e+\dot{e}+\frac{(K)^{2}}{2} \sum e\right) K_{v}
\end{aligned}
$$

Where $(\alpha)$ is gain updating factor, $\left(\sum e\right)$ is the integral of error, $(\dot{e})$ is change of error, $(e)$ is error and $\mathrm{K}$ is a coefficient.

\section{Results And Discussion}

Modified PD fuzzy PD Gravity technique was tested to Step response trajectory. In this simulation, to control position of continuum robot the first, second, and third joints are moved from home to the final position without and with external disturbance. The simulation was implemented in MATLAB/SIMULINK environment. These systems are tested by band limited white noise with a predefined $40 \%$ of relative to the input signal amplitude. This type of noise is used to external disturbance in continuous and hybrid systems and applied to nonlinear dynamic of these controllers.

GDA Optimization Controller: In GDA proposed method; controllers performance are depended on the gain updating factor $(K)$ and PD coefficient and gain updating factor. These coefficients are computed by GDA optimization; Figure4.

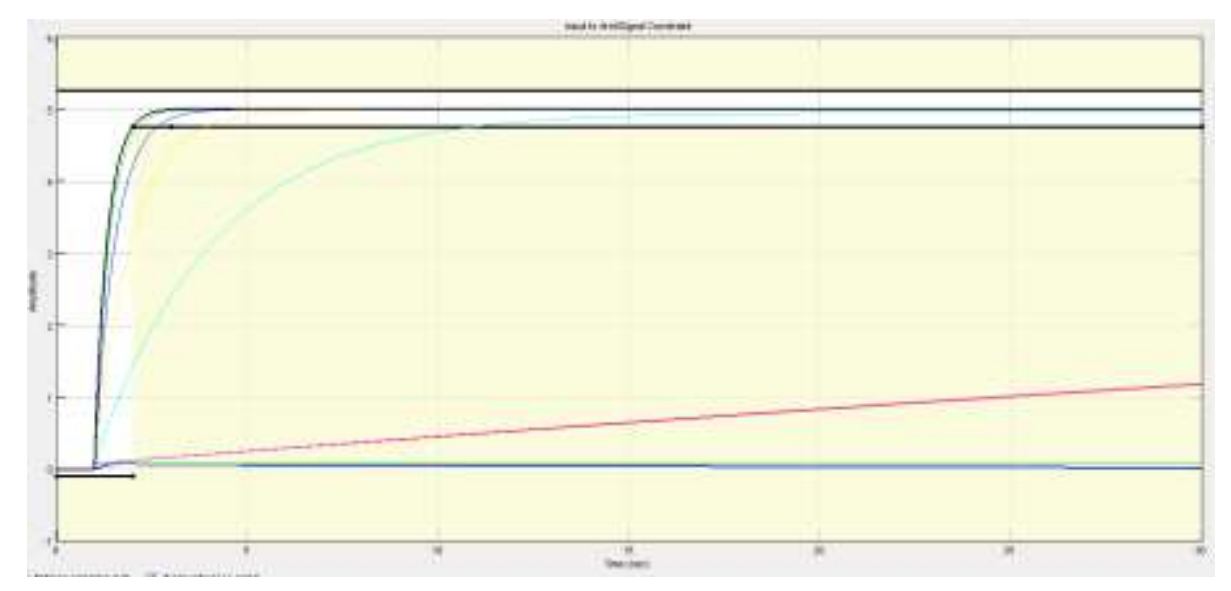

Fig. 4: Trajectory Gradient descent optimization in proposed controller 
Tracking performances: In proposed controller; the performance is depended on the gain updating factor $(K)$ and PD coefficient. These coefficients are computed by gradient descent optimization in the first time and online tune based on adaptive methodology. Figure 5 shows tracking performance in PD gravity and proposed method.

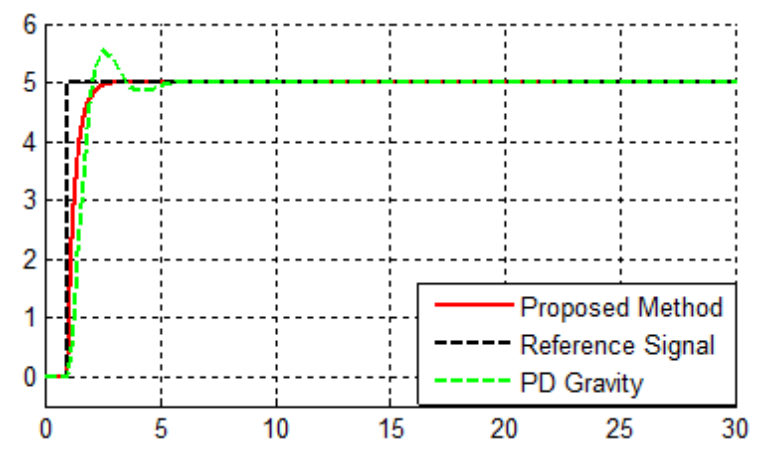

Fig. 5: Proposed method vs. PD gravity

Disturbance rejection: Figure 6 shows the power disturbance elimination in proposed method and PD gravity in presence of disturbance for step trajectory. The disturbance rejection is used to test the robustness comparisons of these controllers for step trajectory. A band limited white noise with predefined of $40 \%$ the power of input signal value is applied to the step trajectory. It found fairly fluctuations in PD gravity trajectory responses but proposed method is more robust.

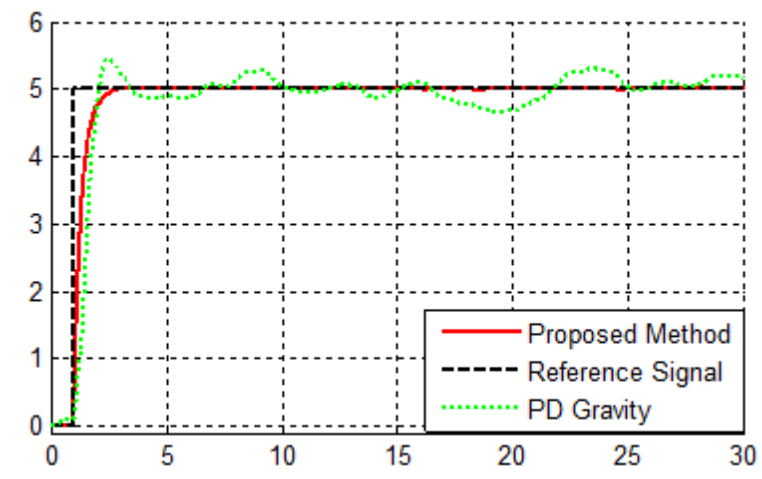

Fig. 6: Proposed method vs. PD gravity: in presence of $40 \%$ disturbance

\section{Conclusion}

The central issues and challenges of non linear control and estimation problems are to satisfy the desired performance objectives in the presence of noises, disturbances, parameter perturbations, un-modeled dynamics, sensor failures, actuator failures, time delays, etc. proposed fuzzy modified PD Gravity online tuning has shown growing popularity in both industry and academia. To improve the optimality and robustness, we have proposed online tuning control for nonlinear systems with general performance criteria. PD gravity provides us an effective tool to control nonlinear systems. Fuzzy inference controller is one of the industrial nonlinear controllers in certain systems. Mixed performance criteria have been used to design the controller and the relative weighting matrices of these criteria can be achieved by choosing different coefficient matrices. The simulation studies show that the proposed method provides a satisfactory alternative to the existing nonlinear control approaches. Online tuning can reject the disturbance and uncertainties more than pure PD gravity.

\section{Acknowledgment}

The authors would like to thank the anonymous reviewers for their careful reading of this paper and for their helpful comments. This work was supported by the SSP Research and Development Corporation Program of Iran under grant no. 2012-Persian Gulf-3C.

\section{References}

[1] G. Robinson, and J. Davies, "Continuum robots - a state of the art,"Proc. IEEE International Conference on Robotics and Automation, Detroit, MI, 1999, vol. 4, pp. 2849-2854.

[2] I.D. Walker, D. Dawson, T. Flash, F. Grasso, R. Hanlon, B. Hochner, W.M. Kier, C. Pagano,C.D. Rahn, Q. Zhang, "Continuum Robot Arms Inspired by Cephalopods, Proceedings SPIE Conference on Unmanned Ground Vehicle Technology VII, Orlando, FL, pp 303-314, 2005.

[3] K. Suzumori, S. Iikura, and H. Tanaka, "Development of Flexible Microactuator and it's Applications to Robotic Mechanisms", Proceedings IEEE International Conference on Robotics and Automation, Sacramento, California, pp. 1622-1627, 1991.

[4] D. Trivedi, C.D. Rahn, W.M. Kier, and I.D. Walker, "Soft Robotics: Biological Inspiration, State of the Art, and Future Research", Applied Bionics and Biomechanics, 5(2), pp. 99-117, 2008.

[5] W. McMahan, M. Pritts, V. Chitrakaran, D. Dienno, M. Grissom, B. Jones, M. Csencsits, C.D. Rahn, D. Dawson, and I.D. Walker, "Field Trials and Testing of "OCTARM" Continuum Robots", Proc. IEEE International Conference on Robotics and Automation, pp. 2336-2341, 2006.

[6] W. McMahan, I.D. Walker, "Octopus-Inspired Grasp Synergies for Continuum Manipulators”, Proc. IEEE International Conference on Robotics and Biomimetics, pp. 945- 950, 2009.

[7] I. Boiko, L. Fridman, A. Pisano and E. Usai, "Analysis of chattering in systems with secondorder sliding modes," IEEE Transactions on 
Automatic Control, No. 11, vol. 52,pp. 2085-2102, 2007.

[8] J. Wang, A. Rad and P. Chan, "Indirect adaptive fuzzy sliding mode control: Part I: fuzzy switching," Fuzzy Sets and Systems, No. 1, vol. 122,pp. 21-30, 2001

[9] M. Bazregar, Farzin Piltan, A. Nabaee and M.M. Ebrahimi, "Parallel Soft Computing Control Optimization Algorithm for Uncertainty Dynamic Systems", International Journal of Advanced Science and Technology, 51, 2013.

[10] Farzin Piltan, M.H. Yarmahmoudi, M. Mirzaei, S. Emamzadeh, Z. Hivand, "Design Novel Fuzzy Robust Feedback Linearization Control with Application to Robot Manipulator", International Journal of Intelligent Systems and Applications, 5(5), 2013.

[11] Sh. Tayebi Haghighi, S. Soltani, Farzin Piltan, M. kamgari, S. Zare, "Evaluation Performance of IC Engine: Linear Tunable Gain Computed Torque Controller Vs. Sliding Mode Controller", International Journal of Intelligent Systems and Applications, 5(6), 2013.

[12] Farzin Piltan, A. R. Salehi \& Nasri B Sulaiman,"Design Artificial Robust Control of Second Order System Based on Adaptive Fuzzy Gain Scheduling", World Applied Science Journal (WASJ), 13 (5): 1085-1092, 2011.

[13] Farzin Piltan, N. Sulaiman, Atefeh Gavahian, Samira Soltani \& Samaneh Roosta, "Design Mathematical Tunable Gain PID-Like Sliding Mode Fuzzy Controller with Minimum Rule Base", International Journal of Robotic and Automation, 2 (3): 146-156, 2011.

[14] Farzin Piltan , N. Sulaiman, Zahra Tajpaykar, Payman Ferdosali \& Mehdi Rashidi, "Design Artificial Nonlinear Robust Controller Based on CTLC and FSMC with Tunable Gain", International Journal of Robotic and Automation, 2 (3): 205-220, 2011.

[15] Farzin Piltan, Mohammad Mansoorzadeh, Saeed Zare, Fatemeh Shahriarzadeh, Mehdi Akbari, "Artificial tune of fuel ratio: Design a novel siso fuzzy backstepping adaptive variable structure control", International Journal of Electrical and Computer Engineering (IJECE), 3 (2): 183-204, 2013.

[16] Farzin Piltan, M. Bazregar, M. Kamgari, M. Akbari, M. Piran, "Adjust the fuel ratio by high impact chattering free sliding methodology with application to automotive engine", International Journal of Hybrid Information Technology (IJHIT), 6 (1): 13-24, 2013.

[17] Shahnaz Tayebi Haghighi, S. Soltani, Farzin Piltan, M. Kamgari, S. Zare, "Evaluation Performance of
IC Engine: linear tunable gain computed torque controller Vs. Sliding mode controller", I. J. Intelligent system and application, 6 (6): 78-88, 2013.

[18] Farzin Piltan, N. Sulaiman, Payman Ferdosali \& Iraj Assadi Talooki, "Design Model Free Fuzzy Sliding Mode Control: Applied to Internal Combustion Engine", International Journal of Engineering, 5 (4):302-312, 2011.

[19] Farzin Piltan, N. Sulaiman, A. Jalali \& F. Danesh Narouei, "Design of Model Free Adaptive Fuzzy Computed Torque Controller: Applied to Nonlinear Second Order System", International Journal of Robotics and Automation, 2 (4):245-257, 2011

[20] A. Jalali, Farzin Piltan, M. Keshtgar, M. Jalali, "Colonial Competitive Optimization Sliding Mode Controller with Application to Robot Manipulator", International Journal of Intelligent Systems and Applications, 5(7), 2013.

[21] Farzin Piltan, Amin Jalali, N. Sulaiman, Atefeh Gavahian \& Sobhan Siamak, "Novel Artificial Control of Nonlinear Uncertain System: Design a Novel Modified PSO SISO Lyapunov Based Fuzzy Sliding Mode Algorithm", International Journal of Robotics and Automation, 2 (5): 298316, 2011.

[22] Farzin Piltan, N. Sulaiman, Iraj Asadi Talooki \& Payman Ferdosali, "Control of IC Engine: Design a Novel MIMO Fuzzy Backstepping Adaptive Based Fuzzy Estimator Variable Structure Control", International Journal of Robotics and Automation, 2 (5):360-380, 2011.

[23] Farzin Piltan, N. Sulaiman, S.Soltani, M. H. Marhaban \& R. Ramli, "An Adaptive Sliding Surface Slope Adjustment in PD Sliding Mode Fuzzy Control For Robot Manipulator", International Journal of Control and Automation, 4 (3): 65-76, 2011.

[24] Farzin Piltan, N. Sulaiman, Mehdi Rashidi, Zahra Tajpaikar \& Payman Ferdosali, "Design and Implementation of Sliding Mode Algorithm: Applied to Robot Manipulator-A Review", International Journal of Robotics and Automation, 2 (5):265-282, 2011.

[25] Farzin Piltan, N. Sulaiman , Arash Zargari, Mohammad Keshavarz \& Ali Badri, "Design PIDLike Fuzzy Controller with Minimum Rule Base and Mathematical Proposed On-line Tunable Gain: Applied to Robot Manipulator", International Journal of Artificial Intelligence and Expert System, 2 (4):184-195, 2011.

[26] Farzin Piltan, SH. Tayebi HAGHIGHI, N. Sulaiman, Iman Nazari \& Sobhan Siamak, "Artificial Control of PUMA Robot Manipulator: A-Review of Fuzzy Inference Engine and 
Application to Classical Controller", International Journal of Robotics and Automation, 2 (5):401-425, 2011.

[27] A. Salehi, Farzin Piltan, M. Mousavi, A. Khajeh, M. R. Rashidian, "Intelligent Robust Feed-forward Fuzzy Feedback Linearization Estimation of PID Control with Application to Continuum Robot", International Journal of Information Engineering and Electronic Business, 5(1), 2013.

[28] Farzin Piltan, N. Sulaiman \& I.AsadiTalooki, "Evolutionary Design on-line Sliding Fuzzy Gain Scheduling Sliding Mode Algorithm: Applied to Internal Combustion Engine", International Journal of Engineering Science and Technology, 3 (10):7301-7308, 2011.

[29] Farzin Piltan, Nasri B Sulaiman, Iraj Asadi Talooki \& Payman Ferdosali, ’Designing On-Line Tunable Gain Fuzzy Sliding Mode Controller Using Sliding Mode Fuzzy Algorithm: Applied to Internal Combustion Engine" World Applied Science Journal (WASJ), 15 (3): 422-428, 2011.

[30] Farzin Piltan, M.J. Rafaati, F. Khazaeni, A. Hosainpour, S. Soltani, "A Design High Impact Lyapunov Fuzzy PD-Plus-Gravity Controller with Application to Rigid Manipulator", International Journal of Information Engineering and Electronic Business, 5(1), 2013.

[31] A. Jalali, Farzin Piltan, A. Gavahian, M. Jalali, M. Adibi, "Model-Free Adaptive Fuzzy Sliding Mode Controller Optimized by Particle Swarm for Robot manipulator", International Journal of Information Engineering and Electronic Business, 5(1), 2013.

[32] Farzin Piltan, N. Sulaiman, Payman Ferdosali, Mehdi Rashidi \& Zahra Tajpeikar, "Adaptive MIMO Fuzzy Compensate Fuzzy Sliding Mode Algorithm: Applied to Second Order Nonlinear System", International Journal of Engineering, 5 (5): 380-398, 2011.

[33] Farzin Piltan, N. Sulaiman, Hajar Nasiri, Sadeq Allahdadi \& Mohammad A. Bairami, "Novel Robot Manipulator Adaptive Artificial Control: Design a Novel SISO Adaptive Fuzzy Sliding Algorithm Inverse Dynamic Like Method", International Journal of Engineering, 5 (5): 399418, 2011.

[34] Farzin Piltan, N. Sulaiman, Sadeq Allahdadi, Mohammadali Dialame \& Abbas Zare, "Position Control of Robot Manipulator: Design a Novel SISO Adaptive Sliding Mode Fuzzy PD Fuzzy Sliding Mode Control", International Journal of Artificial Intelligence and Expert System, 2 (5):208-228, 2011.

[35] M. M. Ebrahimit Farzin Piltan, M. Bazregar and A.R. Nabaee "Intelligent Robust Fuzzy-Parallel Optimization Control of a Continuum Robot
Manipulator", International Journal of Control and Automation, 6(3), 2013.

[36] Farzin Piltan, M.A. Bairami, F. Aghayari, M.R. Rashidian, "Stable Fuzzy PD Control with Parallel Sliding Mode Compensation with Application to Rigid Manipulator", International Journal of Information Technology and Computer Science, 5(7), 2013.

[37] Farzin Piltan, N. Sulaiman, Samaneh Roosta, Atefeh Gavahian \& Samira Soltani, "Evolutionary Design of Backstepping Artificial Sliding Mode Based Position Algorithm: Applied to Robot Manipulator", International Journal of Engineering, 5 (5):419-434, 2011.

[38] Farzin Piltan, N. Sulaiman, Amin Jalali, Sobhan Siamak \& Iman Nazari, "Control of Robot Manipulator: Design a Novel Tuning MIMO Fuzzy Backstepping Adaptive Based Fuzzy Estimator Variable Structure Control”, International Journal of Control and Automation, 4 (4):91-110, 2011.

[39] Farzin Piltan, N. Sulaiman, Atefeh Gavahian, Samaneh Roosta \& Samira Soltani, "On line Tuning Premise and Consequence FIS: Design Fuzzy Adaptive Fuzzy Sliding Mode Controller Based on Lyaponuv Theory", International Journal of Robotics and Automation, 2 (5):381-400, 2011.

[40] Farzin Piltan, N. Sulaiman, Samira Soltani, Samaneh Roosta \& Atefeh Gavahian, "Artificial Chattering Free on-line Fuzzy Sliding Mode Algorithm for Uncertain System: Applied in Robot Manipulator", International Journal of Engineering, 5 (5):360-379, 2011

[41] Farzin Piltan, F. ShahryarZadeh ,M. Mansoorzadeh ,M. kamgari, S. Zare, "Robust Fuzzy PD Method with Parallel Computed Fuel Ratio Estimation Applied to Automotive Engine "International Journal of Intelligent Systems and Applications, 5(8), 2013.

[42] Farzin Piltan, Sadeq Allahdadi, Mohammad A.Bairami \& Hajar Nasiri, "Design Auto Adjust Sliding Surface Slope: Applied to Robot Manipulator", International Journal of Robotics and Automation, 3 (1):27-44, 2011.

[43] Farzin Piltan, Mohammadali Dialame, Abbas Zare \& Ali Badri, "Design Novel Lookup Table Changed Auto Tuning FSMC:Applied to Robot Manipulator", International Journal of Engineering, $6(1): 25-41,2012$.

[44] Farzin Piltan, M. Keshavarz, A. Badri \& A. Zargari, "Design Novel Nonlinear Controller Applied to RobotManipulator: Design New Feedback Linearization Fuzzy Controller with Minimum Rule Base Tuning Method", International Journal of Robotics and Automation, 3 (1):1-12, 2012. 
[45] Farzin Piltan, Mohammad A.Bairami, Farid Aghayari \& Sadeq Allahdadi, "Design Adaptive Artificial Inverse Dynamic Controller: Design Sliding Mode Fuzzy Adaptive New Inverse Dynamic Fuzzy Controller", International Journal of Robotics and Automation, (1):13-26, 2012.

[46] Farzin Piltan, Sadeq Allahdadi, Mohammad A.Bairami \& Hajar Nasiri, "Design Auto Adjust Sliding Surface Slope: Applied to Robot Manipulator", International Journal of Robotics and Automation, 3 (1):27-44, 2012.

[47] Farzin Piltan, F. Aghayari, M. Rashidian \& M. Shamsodini, "A New Estimate Sliding Mode Fuzzy Controller for RoboticManipulator", International Journal of Robotics and Automation, 3 (1):45-60, 2012

[48] Farzin Piltan, Iman Nazari, Sobhan Siamak, Payman Ferdosali, "Methodology of FPGA-Based Mathematical error-Based Tuning Sliding Mode Controller", International Journal of Control and Automation, 5(1), 89-118, 2012.

[49] Farzin Piltan, Bamdad Boroomand, Arman Jahed \& Hossein Rezaie, "Methodology of Mathematical Error-Based Tuning Sliding Mode Controller", International Journal of Engineering, 6 (2):96-117, 2012.

[50] Farzin Piltan, S. Emamzadeh, Z. Hivand, F. Shahriyari \& Mina Mirazaei. " PUMA-560 Robot Manipulator Position Sliding Mode Control Methods Using MATLAB/SIMULINK and Their Integration into Graduate/Undergraduate Nonlinear Control, Robotics and MATLAB Courses", International Journal of Robotics and Automation, 3(3):106-150, 2012.

[51] Farzin Piltan, A. Hosainpour, E. Mazlomian, M.Shamsodini, M.H Yarmahmoudi. "Online Tuning Chattering Free Sliding Mode Fuzzy Control Design: Lyapunov Approach", International Journal of Robotics and Automation, 3(3):77-105, 2012.

[52] Farzin Piltan, R. Bayat, F. Aghayari, B. Boroomand. "Design Error-Based Linear ModelFree Evaluation Performance Computed Torque Controller", International Journal of Robotics and Automation, 3(3):151-166, 2012.

[53] Farzin Piltan, J. Meigolinedjad, S. Mehrara, S. Rahmdel. "Evaluation Performance of $2^{\text {nd }}$ Order Nonlinear System: Baseline Control Tunable Gain Sliding Mode Methodology", International Journal of Robotics and Automation, 3(3): 192-211, 2012.

[54] Farzin Piltan, Mina Mirzaei, Forouzan Shahriari, Iman Nazari, Sara Emamzadeh, "Design Baseline Computed Torque Controller", International Journal of Engineering, 6(3): 129-141, 2012.
[55] Farzin Piltan, Sajad Rahmdel, Saleh Mehrara, Reza Bayat, "Sliding Mode Methodology Vs. Computed Torque Methodology Using MATLAB/SIMULINK and Their Integration into Graduate Nonlinear Control Courses", International Journal of Engineering, 6(3): 142-177, 2012.

[56] Farzin Piltan, M.H. Yarmahmoudi, M. Shamsodini, E.Mazlomian, A.Hosainpour. 'PUMA-560 Robot Manipulator Position Computed Torque Control Methods Using MATLAB/SIMULINK and Their Integration into Graduate Nonlinear Control and MATLAB Courses", International Journal of Robotics and Automation, 3(3): 167-191, 2012.

[57] Farzin Piltan, Hossein Rezaie, Bamdad Boroomand, Arman Jahed. "Design Robust Backstepping on-line Tuning Feedback Linearization Control Applied to IC Engine", International Journal of Advance Science and Technology, 11:40-22, 2012.

[58] Farzin Piltan, S. Siamak, M.A. Bairami and I. Nazari." Gradient Descent Optimal Chattering Free Sliding Mode Fuzzy Control Design: Lyapunov Approach", International Journal of Advanced Science and Technology, 43: 73-90, 2012.

[59] Farzin Piltan, M.R. Rashidian, M. Shamsodini and S. Allahdadi." Effect of Rule Base on the FuzzyBased Tuning Fuzzy Sliding Mode Controller: Applied to $2^{\text {nd }}$ Order Nonlinear System", International Journal of Advanced Science and Technology, 46:39-70, 2012.

[60] Farzin Piltan, A. Jahed, H. Rezaie and B. Boroomand." Methodology of Robust Linear Online High Speed Tuning for Stable Sliding Mode Controller: Applied to Nonlinear System", International Journal of Control and Automation, 5(3): 217-236, 2012.

[61] Farzin Piltan, R. Bayat, S. Mehara and J. Meigolinedjad. "GDO Artificial IntelligenceBased Switching PID Baseline Feedback Linearization Method: Controlled PUMA Workspace", International Journal of Information Engineering and Electronic Business, 5: 17-26, 2012.

[62] Farzin Piltan, B. Boroomand, A. Jahed and H. Rezaie. "Performance-Based Adaptive Gradient Descent Optimal Coefficient Fuzzy Sliding Mode Methodology", International Journal of Intelligent Systems and Applications, 11: 40-52 2012.

[63] Farzin Piltan, S. Mehrara, R. Bayat and S. Rahmdel. " Design New Control Methodology of Industrial Robot Manipulator: Sliding Mode Baseline Methodology", International Journal of Hybrid Information Technology, 5(4):41-54, 2012. 
[64] AH Aryanfar, MR Khammar, Farzin Piltan, "Design a robust self-tuning fuzzy sliding mode control for second order systems", International Journal of Engineering Science REsearch, 3(4): 711-717, 2012.

[65] Farzin Piltan, Shahnaz Tayebi Haghighi, "Design Gradient Descent Optimal Sliding Mode Control of Continuum Robots", International Journal of Robotics and Automation, 1(4): 175-189, 2012.

[66] Farzin Piltan, A. Nabaee, M.M. Ebrahimi, M. Bazregar, "Design Robust Fuzzy Sliding Mode Control Technique for Robot Manipulator Systems with Modeling Uncertainties", International Journal of Information Technology and Computer Science, 5(8), 2013.

[67] Farzin Piltan, M. Akbari, M. Piran , M. Bazregar. "Design Model Free Switching Gain Scheduling Baseline Controller with Application to Automotive Engine", International Journal of Information Technology and Computer Science, 01:65-73, 2013.

[68] Farzin Piltan, M. Piran , M. Bazregar, M. Akbari, "Design High Impact Fuzzy Baseline Variable Structure Methodology to Artificial Adjust Fuel Ratio", International Journal of Intelligent Systems and Applications, 02: 59-70, 2013.

[69] Farzin Piltan, M. Mansoorzadeh, M. Akbari, S. Zare, F. ShahryarZadeh "Management of Environmental Pollution by Intelligent Control of Fuel in an Internal Combustion Engine“ Global Journal of Biodiversity Science And Management, 3(1), 2013.

\section{Authors' Profiles}

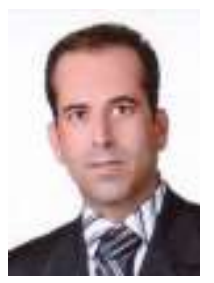

Mansour Bazregar is currently working as a co researcher in Control and Robotic Lab at the institute of advance science and technology, SSP research and development institute. He is a Master in Industrial Management Engineering from Islamic Azad University. His current research interests are in the area of nonlinear control, artificial control system, internal combustion Engine and robotics.

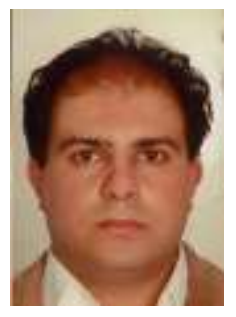

Farzin Piltan was born on 1975, Shiraz, Iran. In 2004 he is jointed the research and development company, SSP Co, Shiraz, Iran. In addition to 7 textbooks, Farzin Piltan is the main author of more than 90 scientific papers in refereed journals. He is editorial review board member for 'international journal of control and automation (IJCA), Australia, ISSN: 2005-4297; 'International Journal of
Intelligent System and Applications (IJISA)', Hong Kong, ISSN:2074-9058; 'IAES international journal of robotics and automation, Malaysia, ISSN:2089-4856; 'International Journal of Reconfigurable and Embedded Systems', Malaysia, ISSN:2089-4864. His current research interests are nonlinear control, artificial control system and applied to FPGA, robotics and artificial nonlinear control and IC engine modeling and control.

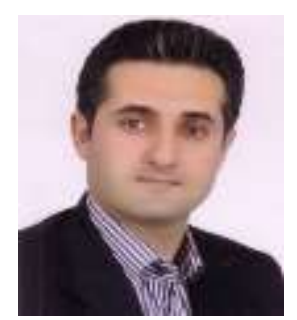

AliReza Nabaee is is currently working as a co researcher in Control and Robotic Lab at the inistitute of advance science and technology, SSP research and development institute. His current research interests are in the area of nonlinear control, artificial control system and robotics.

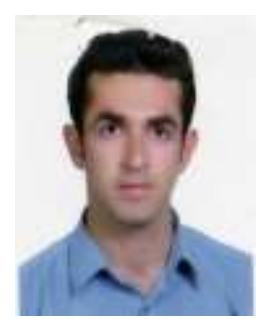

Mohammad Mahidi Ebrahimi is currently working as a co researcher in Control and Robotic Lab at the inistitute of advance science and technology, SSP research and development institute. His current research interests are in the area of nonlinear control, artificial control system and robotics.

How to cite this paper: Mansour Bazregar, Farzin Piltan, AliReza Nabaee, MohammadMahdi Ebrahimi,"Design Modified Fuzzy PD Gravity Controller with Application to Continuum Robot", International Journal of Information Technology and Computer Science(IJITCS), vol.6, no.3, pp.82-94, 2014. DOI: 10.5815/ijitcs.2014.03.10 